\title{
Learning Disorders: From a Tragic to an Epic Perspective on Complexity
}

\author{
MICHEL ALHADEFF-JONES, Editor-in-Chief \\ University of Fribourg (Switzerland) \\ Teachers College, Columbia University (USA) \\ Laboratoire EXPERICE, University of Paris 8 (France)
}

\begin{abstract}
“... I have radically understood that everything which does not carry the mark of disorder eliminates existence, being, creation, life, liberty, and I have understood that all elimination of being, existence, self, creation is rationalizing madness. I have understood that order alone is nothing but bulldozing, that organization without disorder is absolute enslavement. I have understood that we must fear, not disorder, but the fear of disorder, not the subject, but feeble-minded subjectivity which takes itself for objectivity."
\end{abstract}

- Edgar Morin (1977/ 1992, p. 395)

Recognizing and taking into consideration multiple forms of disorder constitutes a privileged way to grasp what is at the core of the idea of complexity. Considering the recent history of Western thought, contemporary complexity theories are indeed embedded into the development of scientific contributions that integrate the idea of disorder in the understanding of natural phenomena.

In physics, the discovery of three fundamental forms of disorder has changed modern theories. First, the phenomenon of entropy, highlighted by Carnot and formulated by Clausius in 1850; then the principle of indetermination associated with the work of Planck in micro-physics, and the discoveries made since the 1920's in astrophysics, demonstrate the extension of the universe and its possible explosive origin. At every scale, the physical universe appears as the product of disorders. From an ontological perspective, the principle of entropy brought scientists to revisit some core assumptions about the nature of the world: ordered and organized forms of physical phenomena are mathematically the most improbable. The principle of indetermination goes beyond the idea of disorder made of degradation and disorganization; it stresses the possibility of disorder existing at the level of particles constitutive of the physical world: particles can no longer be considered elementary objects clearly definable, retrievable, measurable. Therefore, the most fundamental elements of our reality cloud up, dissociate themselves under the observer's gaze (Morin, 1977/1992). Finally, the 
explosive nature of the universe (e.g., big bang theory) introduces the idea of a genesic disorder, located at the origin of the emergence of organized phenomena. With Prigogine's discovery of "dissipative structures" and the progress made in the study of non-linear dynamics, it appears that disordered phenomena and organizing phenomena are complementary: For instance calorific fluxes, in a condition of instability, can be transformed into structures or organized forms (e.g., Bénard's convection pattern). "It is therefore possible to explore the idea of a universe which constitutes its order and its organization in turbulence, instability, deviance, improbability, energy dissipation." (Morin, 1977/1992, p. 38). The idea of disorder appears as a rich and fundamental notion: "... there is not a disorder (as there was an order) but several disorders: inequality, agitation, turbulence, chance encounter, rupture, catastrophe, fluctuation, instability, disequilibrium, diffusion, dispersion, positive retroaction, runaway, explosion" (ibid., p. 46). Such discoveries had significant impact in various disciplines. Since the 1950's, scientists started to conceive living organizations based on their internal dynamics: Von Neumann's self-reproducing automata function with disorder; Von Foerster's "order from noise principle" suggests that self-organized living organizations are constructed with disorder; later, in biology, Atlan's formulation of "chance as organizer" (see Alhadeff-Jones, 2008; Morin, 1977/1992). Contemplating physical forms of disorder, Morin reminds us:

Disorder is not an entity in itself; it is always relative to energic [sic], interactional, transformative, or dispersive processes. Its characters are modified according to these processes. As we have seen, there is not one disorder: there are several overlapping and interfering disorders: there is a disorder in disorder. There are orders in the disorder. (Morin, $1977 / 1992$, p. 72, stressed by the author)

The idea of disorder refers indeed to heterogeneous phenomena that can be interpreted as destructive and productive. On one hand:

Agitations and dispersions have a random, disorganized and eventually disorganizing character. Perturbations and accidents are random events which threaten organization; at the core of a communicational / informational organization, disorders appear as "noise" that can lead to errors in communication, computation and memorization. (Morin, 1980, p. 365, my translation)

On the other hand:

Disorder is active everywhere. It permits (fluctuations), nourishes (encounters) the constitution and the development of organized phenomena. It co-organizes and disorganizes alternately and simultaneously. All becoming is marked by disorder: ruptures, schisms, deviances are conditions of creation, birth, morphogenesis. (Morin, $1977 / 1992$, p. 72)

From physics and biology to psychology, sociology and anthropology, it seems legitimate to question the role of disorder in the everyday life. Considering phenomena such as chance, hazard, agitation, dispersion, perturbation, accident, noise, error, it seems therefore critical for practitioners and researchers in education to focus their attention on complementary, antagonistic and concurring relationships between order and disorder, and to question the role they play in the processes through which education and learning self-organize themselves. Disorder appears therefore as a key concept that has to be considered in education, in conjunction with the ideas of order, interaction and organization.

Promoting a conception of education that acknowledges and embraces the role played by heterogeneous forms of disorder appears therefore as a critical project. It raises at least three questions, respectively from an epistemological, educational and ethical perspective. 


\section{How does one conceive disorders at the scale of the everyday life?}

The way the idea of disorder is conceived in educational theory and in practice cannot be taken for granted. As a result of their heavy anchorage in physics, chemistry, biology, cybernetics, information and communication theories, etc., some of the concepts framing the contemporary understanding of complexity in connection with the study of education present a risk of producing pseudo-scientific analogies grounding new theories and practices in illegitimate frames of interpretation (Alhadeff-Jones, 2008). From an epistemological and theoretical perspective, physical forms of disorder (e.g., entropy) are not ruled by the same principles that operate in biological (e.g., effects of fever), psychological (e.g., erratic behavior) or social (e.g., social uprising) forms of disorder. At the anthropological level, the idea of disorder can be interpreted in different ways, depending on the forms of order or organization it refers to (e.g., balance, chronology, classification, coherence, discipline, distribution, equilibrium, harmony, hierarchy, morality, plan, rule, standard, symmetry, etc.) It is therefore crucial to pay attention to these distinctions and clarify the meaning of the words we use in order to avoid the pitfalls of eclecticism.

In this perspective, the articles, responses and vignettes published in this issue of Complicity contribute to enrich one's understanding of the role played by specific forms of order and disorder, as well as the complexity of their relationships. Such a finality is at the core of Joakim Larsson and Bo Dahlin's contribution "Educating far from Equilibrium: Chaos Philosophy and the Quest for Complexity in Education". Considering the relationships between chaos and order, the authors question their significance in pedagogy. Because "[t]he question of arriving at a proper balance between [Chaos and Order] has truly been a reoccurring theme in ancient times, the Renaissance, as well as modern literature", Larsson and Dahlin explore contributions going beyond complexity and chaos theories, in order to enrich our understanding with reflections rooted in the reinterpretation of Ancient Greek tragedy, as well as the philosophy of Nietzsche, Schiller, Deleuze and Guattari. Revisiting the meaning of "chaos" appears therefore as a relevant strategy in order to challenge the preponderance traditionally given to the role of "order" in education, and question the everyday strategies that can be used to reestablish balance between order and disorder. In her response to Larsson and Dahlin's article, Inna Semetsky stresses the crucial role played by an "anti-dualistic" epistemology in order to promote a more integrative and dynamic conception embracing the complexity of the relationships between order and disorder. Her contribution is particularly valuable as it discusses the evolution of a way of knowing privileging a principle of complementarity and therefore moving from an either/or to a both/and perspective. In his paper "Turbulence, Perturbance, and Educational Change", Brian Beabout invites us to question the role of disorder - and its relationship with intentionality - in the everyday life of people involved in the school system. Arguing for the distinction between "turbulence" and "perturbance", Beabout uses such a semantic artifact to critically discuss the role of disruption as a strategy for implementing changes. In his paper, Bernard Ricca invites us to envision an approach to education that challenges commonplace teaching methods, because it considers, at the core of teaching, phenomena that may be perceived as expressions and/or sources of disorder: first, the presence of growth, which requires one to acknowledge the historicity, autopoeitic and creative properties of a learning process; second, the presence of mutual interactions, which requires one to acknowledge mutual influences without reducing a system to its parts; and finally, non-linear connectedness, which requires one to acknowledge how the actors of a system and the system as well are enmeshed with each others. In her response to Ricca's paper, Lindsay Hetherington discusses the critical role of "interruption" and "differences" - both being potential sources of disorder - as starting points for creating new possibilities in the classroom. 


\section{How does one learn to embrace disorders?}

Nowadays, most institutions, including schools, universities and science, shape and are shaped by a tragic way of knowing. As Whitehead (1926/2011, pp. 10-11) formulated it "[f]ate in Greek Tragedy becomes the order of nature in modern thought.... [t]he essence of dramatic tragedy is not unhappiness. It resides in the solemnity of the remorseless working of things." According to a tragic way of knowing, knowledge and ignorance are inversely proportional; not being able to understand, explain or predict a phenomenon is the sign that we do not possess yet the adequate cognitive tools (Munari, 1993/2000). For those who embrace such a way of knowing, "the discovery of complexity can only be experienced as destabilizing and therefore tragic" (ibid., p.60, my translation). ${ }^{1}$

Following Elkana (1981), Munari (1993/2000, p. 60) suggests that complexity requires an epic way of knowing, characterized by the fact that the subject "... is not threatened by the discovery of complexity: on the contrary, he is stimulated and enthusiastic about it." According to this perspective, embracing disorder is almost playful. Indeed, if we presuppose "... that anything can happen; that whatever has happened could have happened otherwise (the epic theater) then our historical quest is at most for necessary conditions: 'Why did it happen that way, though it could have happened otherwise?'” (Elkana, 1981, p. 5). From an educational perspective, the question becomes therefore: How does one develop and promote such an epic way of knowing?

The authors in this issue of Complicity address this question in multiple ways. Larsson and Dahlin suggest that embracing complexity "... does not always have to involve grand designs of revolution; it can also find realization in the small resistances, common negotiations and perspective changes that occur on a daily basis in ours schools - and in our lives." It is above all a dynamic play between the children and situations' creative forces and the societal forms of order, form and structure inherent to any teaching settings. For Semestky, such a dynamic play requires creative leadership and the ability to coordinate, balance and integrate opposites and creative tensions, in order to promote creative breakdown of the status quo. Beabout invites us to consider the way we actively and collectively promote "perturbance", as a way to examine and respond to the perception of the turbulent forces that impact our institutions. Considering the consequences of different change strategies, his contribution provides the reader with a typology in order to nuance their respective impact on the educational system. In his paper, Ricca identifies at least four enmeshed paths that should be considered within teachers' professional development: first, accepting that as an educator, one's knowledge and one self get transformed by those we aim to transform (mutual influence); second, recognizing that learners' growth occurs among peers and in a community which grow simultaneously (enculturation); third, paying attention to one's own implications and

\footnotetext{
${ }^{1}$ Such a tragic way of knowing is also present in many - if not most - of contemporary contributions associated with the idea of complexity. When complexity is considered as an ontological dimension of the object of study, it may be assumed that its understanding supposes its reduction to specific characteristics and representation through a set of all-embracing algebraic expressions. Its states and behaviors can in these views be described and calculated with certainty, following a computing process. In these perspectives, the evolution of this kind of system can be predicted, more or less accurately, through programmable algorithms. The possibilities are considered as foreseeable. The behaviors observed are considered as being explainable, and then predictable, by a theory, a rule, or an invariant structure. If the computational capacity of the observer practically limits such a prediction, the development of more sophisticated computing devices allows its advocates to believe in the great potential of this position (see Alhadeff-Jones, 2008). Following Ardoino (2000), I assume here that such a perspective translates an understanding of the world as (hyper-) complicated and waiting to be disentangled, where complexity supposes instead the fundamental non-simplicity of studied phenomena.
} 
multiple belongings through a self-reflective process; and fourth, being sensitive to the flow of a classroom and develop a capacity of improvisation. In her response to Ricca's paper, Hetherington, influenced by Osberg and Biesta's "pedagogy of interruption", stresses the crucial role of the educator (including the teachers' educator), whose responsibility is "to use ongoing, reflection-as-assessment within interactions in order to consciously interrupt mechanistic, iterative orientations towards learning particular skills or content that meet pre-defined goals".

\section{How does one negotiate the ethical dimension of working with, against and through disorders in education?}

At the scale of the everyday life, when one considers human understanding (entendement), the idea of disorder has to be associated with the loss of certainty. It raises fundamental questions related to the way one conceives the limitations experienced by any observer:

... disorder is precisely what, in an observer, gives rise to uncertainty, and uncertainty tends to make the uncertain return to itself and be examined, and that all the more so because, when order is an objective, disorder is first of all taken as a deficiency of subjectivity. Thus, faced with any disorder, we inevitably ask the question: is it not the irrationalizable form of a complexity beyond the reach of our understanding? Thenceforth, the problem not only of the insufficiencies of our knowledge, but also of the limits of our understanding tends to be inscribed in every vision of the world which allows for disorder. (Morin, 1977 / 1992, p. 86)

The presence of disorders represents both a catalyst of growth as well as a threat for the development of an organized system (e.g., a learner, a group, an organization, etc.) Because they involve the potentiality of a crisis, which may be fatal for the system itself, disorders have to be regulated and controlled. At the same time, because they open a window on the fundamental diversity of paths that an evolving situation can follow, their recognition constitutes a crucial step in order to develop a complex and critical understanding of what is at stake. Embracing disorders - and the limits of one's own understanding - requires the development of critical ways of knowing. It invites one to conceive new forms of self-eco-critique: an organized capacity emerging from the recursive loop involving both the critique of one's environment, as well as one's own self-critique (Alhadeff-Jones, 2010). Learning about disorder, as much as learning from disorder, depends fundamentally on the capacity of researchers, practitioners, and learners to question both the limits and the nature of the tensions experienced when they go beyond their comfort zone (Alhadeff-Jones, 2007). Thus, confronting disorders (chance, hazard, agitation, dispersion, perturbation, accident, noise, error, etc.) invites one to conceive both, others' and one's own limitations (the limits of what can be felt, thought, known, done, etc.) It requires considering seriously, but also playfully, the learning involved by the experience of otherness (altérité). It is needed in order to accommodate oneself to such limitations, but also - and above all - to question the cost and the means required in order to transgress them. Promoting a complex understanding of disorders in education requires therefore one to identify the resources facilitating the recognition, the acceptance, as well as the possible transgression of the limitations they introduce. In education, adopting such a position raises numerous challenges (Alhadeff-Jones, 2007, 2012). Because learning to embrace disorders goes against almost everything taught in formal education, it brings one to question the core assumptions that frame one's understanding of what learning is about. Finally, embracing disorders and uncertainty, through the adoption of an epic way of knowing, requires some form of dedication. Because "organization without disorder is absolute enslavement" (Morin, 1977/1992, p. 395), learning to embrace disorders becomes an act 
loaded with an ethical value. As such it can never be taken for granted.

\title{
About the new editorial team of Complicity
}

With this second issue of the year, it is my great pleasure to welcome new members to the editorial team of Complicity. Brian Beabout (University of New Orleans, USA) joins William E. Doll and Deborah Osberg as an Associate Editor. Michelle Jordan (Arizona State University, USA), Winifred Hunsburger (The Bishop Strachan School, Canada), and Randa Khattar (Charles Sturt University, Canada) have joined the team as Copy Editors. Noel Gough (La Trobe University, Australia) is now Editor in charge of the Semantic Play section of the journal. I am particularly glad that all of them have joined with enthusiasm the journal's editorial team, and I truly look forward to pursue this collaboration in order to continue to address the challenging task of providing the readers of Complicity: An International Journal of Complexity and Education, organized reflections about the orders and disorders of complexity in education.

\section{References}

Alhadeff-Jones, M. (2007). Beyond the heterogeneity of critique in Education: Researchers' experiences of antagonisms and limits as transformative learning opportunities. In P. Cranton, \& E. Taylor (Eds.) Proceedings of the $7^{\text {th }}$ International Transformative Learning Conference (pp. 1-6). Albuquerque, NM: University of New Mexico College of Education, Central New Mexico Community College.

Alhadeff-Jones, M. (2008). Three generations of complexity theories: Nuances and ambiguities. Educational Philosophy and Theory, 40(1), 66-82.

Alhadeff-Jones, M. (2010). Challenging the limits of critique in education through Morin's paradigm of complexity. Studies in Philosophy and Education, 29(5), 477-490.

Alhadeff-Jones, M. (2012). Transformative learning and the challenges of complexity. In E.W. Taylor, P. Cranton, \& Associates, Handbook of Transformative Learning: Theory, Research and Practice (pp. 178194). San Francisco: Jossey-Bass.

Ardoino, J. (2000). Les avatars de l'éducation. Paris: PUF.

Elkana, Y. (1981). A programatic attempt at an anthropology of knowledge. In E. Mendhelson, \& Y. Elkana (Eds.), Sciences and cultures (pp. 1-76). Dordrecht, Holland: Reidel Publishing.

Morin, E. (1977/1992). Method. Towards a study of humankind (volume 1: The nature of nature) (J.L.R. Bélanger Trans.). New York: Peter Lang.

Morin, E. (1980). La méthode (volume 2: La vie de la vie). Paris: Seuil.

Munari, A. (1993/2000). Le savoir retrouvé. Genève, Suisse: Université de Genève.

Whitehead, A.N. (1926/2011). Science and the modern world. New York: Cambridge University Press.

\begin{abstract}
About the Author
Michel Alhadeff-Jones is a Lecturer at the University of Fribourg (Switzerland), and an Adjunct Assistant Professor at Teachers College, Columbia University (USA). He also works as an independent researcher associated with the Laboratoire EXPERICE at the University of Paris 8 (France). Beside his function as Editor-in-Chief of Complicity, he is a Consulting editor for the international journals Adult Education Quarterly and Journal of Transformative Education, an Editorial board member of the international French-speaking journal of adult education Pratiques de Formation / Analyses, the international journal of biographical research Le Sujet dans la Cité, and the Polish journal in educational sciences Teraźniejszość - Człowiek - Edukacja. Email: complicity.journal@gmail.com Website: www.sunkhronos.org
\end{abstract}

(c) Copyright 2012. The author, MICHEL ALHADEFF-JONES, assigns to the University of Alberta and other educational and nonprofit institutions a non-exclusive license to use this document for personal use and in courses of instruction provided that the article is used in full and this copyright statement is reproduced. The author also grants a non-exclusive license to the University of Alberta to publish this document in full on the World Wide Web, and for the document to be published on mirrors on the World Wide Web. Any other usage is prohibited without the express permission of the author. 